\title{
Retrograd İntrarenal Cerrahi; Hangi Hastaya?
}

\author{
Bilal Eryıldırım ${ }^{1}$
}

1Sağlık Bilimleri Üniversitesi, Dr. Lütfi Kırdar Kartal Eğitim ve Araştırma Hastanesi, Üroloji Kliniği, İstanbul

Giriş

$\dot{U}^{\bullet}$ riner sistem taş hastalığının tedavisinde kullanılan yöntemler son yıllarda önemli bir değişim geçirmiştir. 1980 öncesi tüm üriner sistem taş hastaları açık cerrahi girişim ile tedavi edilir iken, vücut dışı şok dalgalarıyla taş kırma (SWL) yönteminin bulunması ile 80'li yıllardan sonra taşların büyük çoğunluğu SWL ile tedavi edilmeye çalışılmıştır. Doksanli yıllarda ise teknolojinin katkısı ile endoskopik ekipmanların ve görüntüleme yöntemlerinin gelişmesi; üreteroskopi (URS) ve perkütan nefrolitotomi (PNL) gibi minimal invaziv yöntemlerin yoğun bir şekilde kullanılmaya başlanmasını sağlamıştır. Üreteroskopi önceleri sadece distal üreteral taşların tedavisi için kullanılmıştır. İlerleyen yıllarda fleksible üreterorenoskopların devreye girmesi, endoürolojik yöntemlerin taş hastalığındaki önemini arttırmıştır. Günümüzde üst üriner sistem taşları da retrograd intrarenal cerrahi (RİRC) ile başarılı bir şekilde tedavi edilebilmektedir.

Üriner sistem taş hastalığı tedavisinde kullanılacak en uygun yöntemi seçmek başarıyı arttırırken, komplikasyonları da azaltacaktır. Her yöntemin avantajları olduğu kadar dezavantajları olduğu da unutulmamalıdır. SWL, hastaların en çok tercih ettiği, anestezi gerektirmeyen ve diğer yöntemlere göre daha az invaziv bir yöntemdir. Ancak özellikle büyük taşlar ve alt kaliks taşlarında düşük taşsızlık oranı en önemli dezavantajıdır. PNL, yüksek taşsızlık ve düşük reoperasyon oranları ile başarılı bir yöntem olarak kabul edilebilir, PNL ile \% 90'a varan taşsızlık oranları bildirilmektedir $(1,2)$. Ancak yüksek komplikasyon oranları nedeniyle bazı otörler tarafından bu yöntemin minimal invaziv bir yöntem kabul edilemeyeceği yönünde görüşler de mevcuttur. Günümüzde komplikasyonları azaltmak amacıyla PNL operasyonu daha minyatür aletler kullanılarak yapılmaya çalışılmış ve mini-PNL, ultramini-PNL teknikleri tanımlanmıştır. RİR, PNL'ye göre az invaziv, düşük komplikasyon oranları olan "outpatient" bir prosedürdür, ancak taşsızlık oranları konvansiyonel PNL'ye göre düşük, operasyon zamanı ve reoperasyon oranı daha yüksektir.

Taş hastalığının tedavisinde uygun tedavi seçimi başarının temel belirleyicisidir. Bu kararı verirken cerrah, taşın lokalizasyonu ve boyutu, hastanın özellikleri, böbrek anatomisi ile birlikte kendi deneyimi ve sahip olduğu ekipmanı da göz önünde bulundurmalıdır. Tüm cerrahi branşlarda olduğu gibi ürolojide de süreç en az invaziv yöntemi kullanarak komplikasyonları azaltmak yönündedir. Ancak bunu yaparken operasyon başarısını da düşürmemek temel başarı ölçütü olacaktır.

\section{Retrograd İntrarenal Cerrahi}

\section{Tarihçe}

İlk olarak 1964 yılında fleksible üreterorenoskopi yöntemi tanımlanmakla beraber, ilk kullanilan üreterorenoskoplar çalışma kanalı olmayan, defleksiyon özellikleri çok zayıf aletlerdi ve tanısal amaçlı kullanılmaktaydı $(3,4)$. İlk retrograd intrarenal cerrahi (RİRC) işlemi ise; 1983 yılında Huffman ve ark.'ları tarafından böbrek pelvis taşlarının rijid URS ve ultrasonik litotriptör kullanılarak tedavi edilmesiyle gerçekleştirilmiştir (5). Böbrek taşlarında fleksible URS kullanımı ile ilgili ilk geniş seri 1990 yılında Fuchs ve ark.'ları tarafından yayınlanmıştır. Araştırmacılar, 1-2 hafta süreyle ürete $\neg$ ral mekanik dilatasyon uyguladiktan sonra fleksible üreteroskopla böbrek taşlarına müdahale etmiş ve 208 hastalık ilk RİRC serisini yayınlamışlardır. Yaklaşık \%87 oranında taşsızlık sağlanan bu seride iki hastada gelişen sepsis dışında komplikayon bil $\neg$ dirilmemiştir (6). RİRC operasyonlarında holmium lazerin 1995 yılında kullanılmaya başlanması en büyük gelişme olmuştur. Holmiyum-YAG lazer tüm taş kompozisyonlarında etkili, \%100'e varan fragmantasyon sağlayan bir yöntem olarak litotripside altın standart haline gelmiştir. 1998 yılında Grasso ve ark.'ları fleksible URS + holmium lazer kombinasyonu ile ilgili ilk seriyi yayınlamışlardır (7).

\section{RiRC-Teknolojik Gelișmeler}

Özellikle son yıllarda RİRC'in endikasyonları giderek genişlemekte, kullanım sıklığı hızlı bir şekilde artmaktadır. Bunun nedeni endoürolojide en az invaziv yöntemi tercih etme eğiliminin artması ve fleksible üreterorenoskopi teknolojisinde yaşanan gelişmelerdir. Artık uç kısımları daha ince, lümenleri daha kalın ve daha dayanıklı yeni jenerasyon fleksible üreterorenoskoplar kullanılmaya başlamış ve bunların maliyetlerinde de düşüş olmuştur. Yeni jenerasyon fleksible üreterorenoskopların uç kısımları 5.3-9 F arasında, çalışma kanalları ise 2.4-4 F arasında (en sık 3.6 F) değişmektedir.

Yeni jenerasyon fleksible üreterorenoskopların manevra kabiliyetleri de yüksektir. 275 ye kadar fleksiyon ve defleksiyon yapabilmektedir. İki taraflı yüksek manevra kabiliyetine sahip bu cihazlar sayesinde böbreğin her noktasına daha rahat ulaşabilme imkanı ortaya çıkmıştır. Ayrıca digital görüntü sağlayan fleksible üreterorenoskopların kullanılmaya başlanması görüntü kalitesini önemli derecede arttırmıştır.

RIRC'de önemli bir devrim yaratan lazer kullanımı ve bu lazerlerin daha güçlü olanlarının kullanılmaya başlaması, bunlara ek olarak yeni taş çıkarma aletlerinin (Flat wire basket, Piranha, BIGopsy forceps vb.) kullanılması taşsızlık 


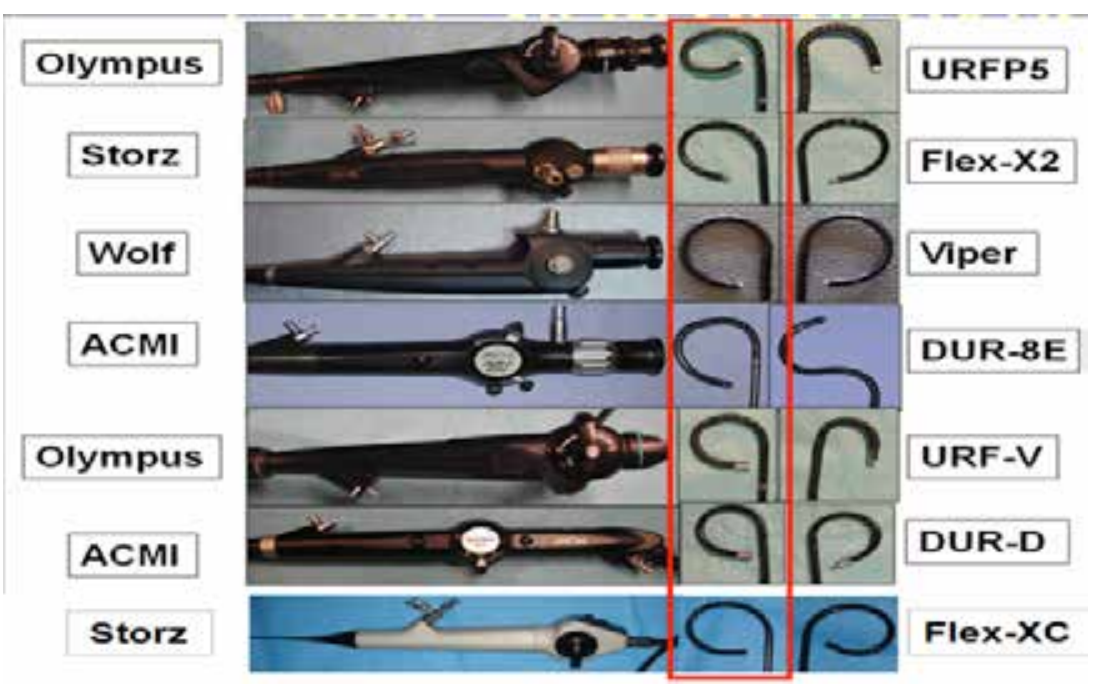

Resim 1: Yeni jenerasyon fleksible üreterorenoskoplar

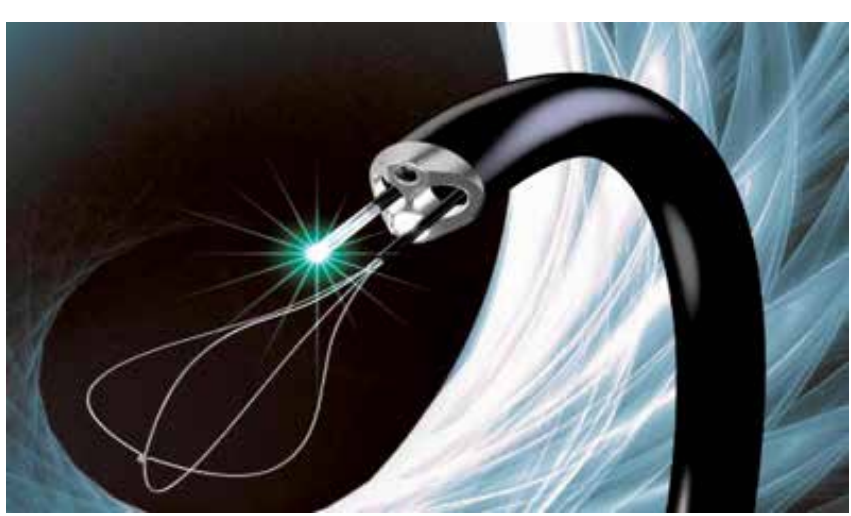

Resim 2: Çift lümenli fleksible üreterorenoskop

oranlarının artmasını sağlayan diğer nedenlerdir.

Yakın zamanda çift lümenli fleksible üreterorenoskopların da kullanılmaya başlanması önemli bir teknolojik gelişme olmuştur. Bu üreterorenoskopun 3.3 F genişliğinde iki adet çalışma kanalı mevcuttur.

\section{RiRC Endikasyonları}

RİRC endikasyonlarını taş dışı ve taş hastalarındaki endikasyonlar olarak 2 kısımda değerlendirmek daha doğru olur.

\section{Taş dışı endikasyonlar}

Hematürinin araştırılması, üst üriner sistem kaynaklı pozitif sitolojisi olan hastaların değerlendirilmesi, üst üriner sistem TCC tedavisi (Holmium, Nd:YAG Lazer, elektrofulgurasyon), üreteropelvik bileşke darlı̆̆ 1 veya intrarenal stenoz tedavileri ve üst üriner sisteme migrate olmuş yabancı cisimlerin çıkarılmasıdır.

\section{Taş ile ilgili endikasyonlar}

Avrupa ve Amerika üroloji kılavuzlarında $2 \mathrm{~cm}$ 'den küçük taşlarda RİRC'in önemli bir tedavi alternatifi olduğu belirtilmektedir. Ayrıca PNL'nin kontrendike olduğu durumlarda 2 cm'den büyük taşlarda da RİRC'nin ilk tedavi seçeneği olabileceği belirtilmektedir. Bunun yanında PNL'nin cerrahı ve hastayı korkutan komplikasyonları nedeniyle, son yıllarda $2 \mathrm{~cm}$ 'den büyük taşlarda da birden fazla seans ihti- malini göz önünde bulundurarak RİRC'in etkili bir yöntem olduğunu bildiren metaanalizler de mevcuttur (8).

Bunlara ek olarak bazı durumlarda RİRC en güvenli ve etkili yöntem olarak öne çıkmaktadır;

\section{Düzeltilemeyen koagülopatiler}

SWL ve PNL bu hastalarda kontrendikedir. Bu hastalara ek olarak antitrombotik ilaç kullanan ve bu ilaçların kesilmesinin uygun olmadığı hastalarda da RİRC en güvenli yöntemdir $(9,10)$. Turna ve ark.'ları kumadin kullanan hastalarda RİRC işleminin kumadin kullanmayan hastalar ile benzer etkinlik ve güvenilirlilikte olduğunu bildirmiştir (11).

\section{Eş zamanlı böbrek ve üreter taşı}

Eş zamanlı böbrek ve üreter taşı bulunan veya bilateral küçük boyutlu böbrek taşı bulunan hastalarda RİRC tek seansta taşsızlık sağlayabilen etkili ve güvenli bir yöntemdir. Ayrıca tek seansta taşsızlık sağlanabilmesi ek girişim ve operasyon ihtiyacını da ortadan kaldıracaktır $(12,13)$.

\section{Alt kaliks tașları}

Alt kaliks taşlarında özellikle de dar infundibulopelvik açı, dar ve uzun kaliks boynunun olduğu hastalar ile sert kompozisyona sahip taşlarda; SWL başarısı oldukça düşüktür. Endoürolojik yöntemlerle karşılaştırıldığında SWL'nin taşsızlık oranlarının düşük, ek girişim oranının fazla ve tedavi sürecinin uzun olduğunu bildiren pek çok yayın mevcuttur $(14,15) .2$ cm'den büyük alt kaliks taşlarında PNL tercih edilecek yöntemdir. $2 \mathrm{~cm}$ 'den küçük alt kaliks taşlarında ise RIRC, PNL ile karşılaştırılabilir taşsızlık oranlarına ulaşabilmektedir (16). Ayrıca PNL'nin komplikasyonlarının çokluğu göz önüne alındığında RİRC'in güvenli bir yöntem olarak tercih edilebileceğini söyleyebiliriz.

\section{Aşırı Obez Hastalar}

Obez hastalarda RİRC etkin ve güvenilir bir tedavi modalitesi olarak öne çımaktadır. RİRC ile obez hastalarda, obez olamayanlara benzer taşsızlık ve komplikasyon oranları elde edildiğini gösteren çalışmalar mevcuttur (17). Cilt-taş mesafesinin 10 'cmden fazla olduğu obez hastalarda SWL'nin başarısı azalmaktadır. Ayrıca obez hastalarda PNL'ninde etkinliğinin azaldığı bildirilmektedir (18). 


\section{Böbrek anomalisi olan hastalar}

Atnalı böbrek, pelvik yerleşimli böbrek, kalisyel divertikül gibi böbrek anomalilerinde RİRC bazı ürologlar tarafından ilk tedavi seçeneği olarak görülmektedir $(19,20)$. Bunun en önemli sebebi, bu hastalarda SWL'nin anormal anatomiye bağlı pozisyonel zorluklar ve odaklama problemi nedeniyle başarısının düşük olması, PNL'nin ise komşu organ ve vasküler yaralanma riskinin yüksek olmasıdır.

\section{Iskelet deformitesi olan hastalar}

$\mathrm{Bu}$ hastalarda da pozisyonel problemler, odaklama ve renal akses problemleri, ayrıca artmış komşu organ ve vasküler yaralanma riski SWL ve PNL prosedürlerini zorlaştırmaktadır. Bu hastalarda da RİRC etkili ve güvenli bir yöntem olarak tercih edilmektedir.

\section{RiRC Kontrendikasyonları}

RİRC için kesin bir kontrendikasyon yoktur (21). Ancak tedavi edilmemiş üriner sistem enfeksiyonunun yaratacağ ürosepsis riski nedeniyle, operasyon öncesi enfeksiyonun mutlak tedavi edilmesi önerilmektedir (22). Göreceli kontrendikasyonlar ise; antikoagulan kullanımı, fimozis, üretra darlığı, üreteral darlık, üreterosel, çok büyük prostat varlığidir.

\section{RiRC avantajları}

RİRC'in en önemli avantajı gerçek anlamda minimal invaziv bir yöntem olmasıdır. Ayrıca obez, renal anomalisi ve vücut postür bozukluğu bulunan, antikoagülan kullanan hastalarda güvenli ve etkili bir prosedürdür. Yöntemin önemli diğer avantajları; kalkülün direkt görüntü altında kırılabilmesi ve kırılan parçaların işlem esnasında çıkarılabilmesi, tüm taş çeşitlerinin holmium laser kullanılarak parçalanabilmesi ve böbrek alt pol taşlarının, fragmantasyonun daha kolay olabileceği bölüme taşınabilmesidir. PNL ile karşılaştırıldığında daha az radyasyon maruziyeti, daha az hastanede kalma süresi, düşük komplikasyon oranları ve öğrenme eğrisinin daha kısa olması RİRC'in önemli avantajlarıdır.

\section{RiRC Etkinliği ve Güvenirliliği}

Literatürde RİRC'nin taşsızlık oranları \%73.6 ile \%94.1 arasında bildirilmektedir (23). 2015 yılında De ve ark.'ları tarafından yayınlanan, PNL ve RİRC'yi karşılaştıran çalışmaları değerlendiren bir metaanalizde taşsızlık oranlarının klasik PNL'de RİRC'e göre daha yüksek olduğu bildirilmekle birlikte, mini-PNL operasyonları taşsızlık oranlarının RİRC'den daha düşük olduğu tesbiti dikkat çekicidir. Bu metaanalizde mini-PNL, f-URS ile taşa ulaşılamadığında ya da ekipman yokluğunda kullanılacak RIRC'ye alternatif bir yöntem olarak tanımlanmıştır. Komplikasyon oranları ve hastanede kalış süreleri ise RİRC'de anlamlı bir şekilde düşüktür. Ancak operasyon süresinin uzun olması ve reoperasyon gerekliliğinin yüksek olması RİRC'nin dezavantajları olarak belirtilmektedir (23).

Reşorlu ve ark.'ları 2012 yılında RİRC'de operasyon sonrası taşsızlık oranlarını tahmin etmemize yardımcı olabilecek yeni bir skorlama sistemi (Reşorlu-Ünsal Taş skoru) tanımlamışlardır. RİRC uygulanan 207 hastayı değerlendirerek başarı üzerinde etkili olabilecek faktörleri belirlemişlerdir.
Bu çalışmalarında taş boyutunun $2 \mathrm{~cm}$ 'den büyük olması, farklı kalikslerde birden çok taşın bulunması, infundibulopelvik açının 45 den dar olması ve hastalarda atnalı böbrek, pelvik böbrek gibi anomalilerin bulunmasının başarı oranını düşüren faktörler olduğunu belirtmişlerdir (24).

\section{RIRC Komplikasyonları}

RİRC'de tecrübenin artması ve yeni jenerasyon fleksible üreterorenoskopların kullanılmaya başlanmas1 ile birlikte komplikasyonlar oldukça azalmıştır (\%2-6). Komplikasyonları intraoperatif (\%3.6), (mukozal yaralanma, üreteral perforasyon, anlamlı kanama ve üreteral avülsiyon), erken postoperatif (\%6), (ateş veya ürosepsis, sebat eden hematüri ve renal kolik) ve geç postoperatif komplikalyonlar (\% 0.2), (üreteral darlık, sebat eden VUR) olarak sınıflandırabiliriz. Bu komplikasyonların çoğu minör komplikasyonlardır ve müdahale gerektirmez (25).

\section{RiRC; Hangi Hastaya?}

- 2 cm'den küçük taşlar veya 2 cm'den büyük olmakla birlikte PNL'nin kontrendike olduğu hastalar

- SWL ve PNL'ye uygun olmayan veya bu yöntemlerle başarı saglanamamis hastalar

- SWL ve PNL'nin uygun tedavi modalitesi olmayacağ öngörülen alt kaliks taşları

- Eş zamanlı böbrek ve üreter taşının bulunduğu uygun hastalar

- Düzeltilemeyen kanama bozukluğu olan veya antitrombotik kullanan ve bu ilaçların kesilemediği hastalar

- Aşırı obez hastalar

- İskelet deformitesi bulunan hastalar

- Renal anomalili (Atnalı böbrek, pelvik böbrek, kalisyel divertikül) hastalar

- Nonopak taşlar

- Üriner diversiyonlu hastalar

- Böbrek taşlarının tam olarak temizlenmesinin gerektiği hastalar (pilotlar vb.)

\section{Sonuç}

Son yıllarda endoürolojide önemli gelişmeler yaşanmış, gelişen teknoloji ile birlikte fleksible üreterorenoskoplar daha etkili tedavi araçları haline gelmiştir. Bu sebeple kılavuzlarda RİRC'nin böbrek taşı tedavisinde önceliği artmaya başlamıştır. Maliyet sorununun giderilmesi, cihaz dayanıklılığının arttırılması, daha güçlü lazerlerin devreye girmesi ve daha fazla randomize kontrollü çalışmanın yayınlanması sonrası; RİRC üriner sistem taş hastalığı tedavisinde etkili ve güvenli standart bir tedavi haline gelecektir.

\section{Kaynaklar}

1. Lopes T, Sangam K, Alken P, et al. The Clinical Research Office of the Endourological Society Percutaneous Nephrolithotomy Global Study: tract dilation comparisons in 5537 patients. Clinical Research Office of The Endourological Society Percutaneous Nephrolithotomy Study Group. J Endourol. 2011; 25: 755-762. 
2. de la Rosette J, Assimos D, Desai M, et al. The Clinical Research Office of the Endourological Society Percutaneous Nephrolithotomy Global Study: indications, complications, and outcomes in 5803 patients.; CROES PCNL Study Group. J Endourol. 2011; 25: 11-17.

3. Takagi T, Go T, Takayasu H, et al. Fiberoptic pyelouretero $\urcorner$ scope. Surgery 1971; 70: 661-663.

4. Bush IM, Goldberg E, Javadpour N, et al. Ureteroscopy and renoscopy: a preliminary report. Chic Med Sch Q 1970; 30: 46-49.

5. Huffman JL, Bagley DH, Lyon ES. Extending cystoscopictechniques into the ureter and renal pelvis. Experience withureteroscopy and pyeloscopy. JAMA 1983; 250: 2002-2005.

6. Fuchs GJ, Fuchs AM. Flexible endoscopy of the upper urinary tract. A new minimally invasive method for diagnosis and treatment. Urologe A 1990; 29: 313-320.

7. Grasso M, Conlin M, Bagley D. Retrograde ureteropyeloscopic treatment of $2 \mathrm{~cm}$ or greater upper urinary tract and minor staghorn calculi. J Urol 1998; 160: 346-351.

8. Aboumarzouk OM, Monga M, Kata SG, et al. Flexible ureteroscopy and laser lithotripsy for stones $>2 \mathrm{~cm}$ : a systematic review and meta-analysis. J Endourol 2012; 26: $1257-1263$

9. Watterson JD, Girvan AR, Cook AJ, et al. Safety and efficacy of holmium: YAG laser lithotripsy in patients with bleeding diatheses. J Urol 2002; 168: 442-445.

10. Aboumarzouk OM, Somani BK, Monga M. Flexible ureteros $\neg$ copy and holmium: YAG laser lithotripsy for stone disease in patients with bleeding diathesis: a systematic review of the lit $\neg$ erature. Int Braz J Urol 2012; 38: 298-305.

11. Turna B, Stein RJ, Smaldone MC, et al. Safety and efficacy of flexible ureterorenoscopy and holmium: YAG lithotripsy for intrarenal stones in antico-agulated cases. J Urol 2008; 179: 1415-1419.

12. Goldberg H, Holland R, Tal R, et al. The impact of retrograde intrarenal surgery for asymp $\neg$ tomatic renal stones in patients undergoing ureteroscopy for a symptomatic ureteral stone. J Endourol 2013; 27: 970-973.

13. Alkan E, Avci E, Ozkanli AO, et al. Same-ses $\neg$ sion bilateral retrograde intrarenal surgery for upper urinary system stones: safety and efficacy. J Endourol 2014; 28: 757-762.

14. Srisubat A, Potisat S, Lojanapiwat B, et al. Extracorporeal shock wave lithotripsy (ESWL) versus percutaneous nephrolithotomy (PCNL) or retrograde intrarenal surgery (RIRS) for kidney stones. Cochrane Data $\neg$ base Syst Rev 2009; (4): CD007044.
15. Breda A, Ogunyemi O, Leppert JT, et al. Flexible ureteroscopy and laser lithotripsy for multiple unilateral in $\neg$ trarenal stones. Eur Urol 2009; 55: 1190-1196.

16. Kirac M, Bozkurt ÖF, Tunc L, et al. Comparison of retrograde intrarenal surgery and mini-percutaneous nephrolithotomy in management of lower-pole renal stones with a diameter of smaller than $15 \mathrm{~mm}$. Urolithiasis. 2013; 41: 241-246.

17. Caskurlu T, Atis G, Arikan O, et al. The impact of body mass index on the outcomes of retrograde intrarenal stone surgery. Urology. 2013; 81: 517-521.

18. Fuller A, Razvi H, Denstedt JD, et al. The CROES percutaneous nephrolithotomy global study: the influence of body mass index on outcome. CROES PCNL Study Group. J Urol. 2012; 188: 138-144.

19. Papatsoris AG, Kachrilas S, El Howairis M, et al. Novel technologies in flexible ureteroscopy. Arab J Urol 2011; 9: $41-46$.

20. Atis G, Resorlu B, Gurbuz C, et al. Retrograde intrarenal surgery in patients with horseshoe kidneys. Urolithiasis 2013; 41: 79-83.

21. Türk C, Knoll T, Petrik A, et al. Guidelines on urolithiasis [Internet]. Anheim (NL): Europe $\neg$ an Association of Urology; c2014 [cited 2015 Jan 5]. Available from: http://uroweb.org/wp-content/uploads/22-Urolithiasis_ LR.pdf.

22. Matlaga BR, Lingeman JE. Surgical management of stones: new technology. Adv Chronic Kidney Dis 2009; 16: 60-64.

23. De S, Autorino R, Kim FJ, et al. Percutaneous nephrolithotomy versus retrograde intrarenal surgery: a systematic review and meta-analysis. Eur Urol 2015; 67: 125-137.

24. Resorlu B, Unsal A, Gulec H, et al. A new scoring system for predicting stone-free rate after retrograde intrarenal surngery: the "resorlu-unsal stone score". Urology 2012; 80:512-518.

25. Geavlete P, Georgescu D, Nita G, et al. Complications of 2735 retrograde semirigid ureteroscopy procedures: a single-center experience. J Endourol. 2006; 20: 179-185.

Yazışma Adresi:

Bilal Eryıldırım,

Sağlık Bilimleri Üniversitesi, Dr. Lütfi Kırdar Kartal Ĕgitim ve Araştırma Hastanesi, Üroloji Kliniği, İstanbul

Tel: +905058141215

e-mail: bilaleryildirim@yahoo.com 